Article

\title{
Hydrogel Formulation of Usnic Acid and Antibacterial Activity Test Against Propionibacterium acne
}

\author{
Lili Fitriani ${ }^{1, *}$, Afifah ${ }^{1}$, Friardi Ismed ${ }^{2}$ and Amri Bakhtiar ${ }^{2, *}$ \\ 1 Department of Pharmaceutics, Faculty of Pharmacy, Andalas University, Padang 25163, Indonesia; \\ afifahvividr33@gmail.com \\ 2 The Laboratory of Natural Resource of Sumatra (LBS) and Faculty of Pharmacy Andalas University, \\ Padang 25163, Indonesia; friardi@phar.unand.ac.id \\ * Correspondence: lilifitriani@phar.unand.ac.id (L.F.); amribakhtiar@phar.unand.ac.id (A.B.); \\ Tel.: +62-812-143-20154 (L.F.)
}

Received: 8 November 2018; Accepted: 17 December 2018; Published: 20 December 2018

check for updates

\begin{abstract}
Usnic acid is known for its remarkable antimicrobial activity. The aim of this research was to formulate hydrogel of usnic acid and evaluate the antibacterial activity against Propionibacterium acne. Due to low solubility of usnic acid, solid dispersion was prepared using PVP K-30. In this study, intact usnic acid (UA) and usnic acid-solid dispersion (UA-SD) was formulated in hydrogel using several gelling agents: Aqupec HV-505, sodium alginate and HPMC K 100M. Concentration of each gelling agent was optimized for hydrogel base. All of hydrogel base showed homogenous gel, $\mathrm{pH}$ at range 5.37-6.33 and viscosity in range 259.07-10,759.00 cps. Hydrogel was prepared by dispersing $1 \%$ intact UA and 3\% UA-SD in three different gelling agents. The hydrogel was evaluated for $\mathrm{pH}$, viscosity, stability test for two months and microbiology test. The amount of usnic acid in hydrogel was determined by spectrophotometry UV-Vis. Hydrogel UA showed non-homogenous gel, while hydrogel usnic UA-SD was homogenous. The $\mathrm{pH}$ of all hydrogel was in range 5.5-6.4 and viscosity was 2,017.03-3,866.52 cps. All the hydrogel was stable and diameter inhibition of hydrogel was in a range 20-32 mm. The amount of usnic acid in hydrogel was in range 96.9-99.23\%. In conclusion, hydrogel UA-SD is promising preparation in handling acne.
\end{abstract}

Keywords: usnic acid; hydrogel; Propionibacterium acne; solid dispersion

\section{Introduction}

Usnic acid, a secondary metabolite produced by Usnea sp, is already known for remarkable pharmacological activities including: anti-bacteria [1], antivirus [2], anti-proliferation [3], anticancer [4], antioxidant [5], antipyretic and analgesic [6] and anti-inflammation [7]. Usnic acid has two optical isomers, the (+) and (-) usnic acid, which affected its activity against microorganisms. Both of enantiomers are potent against Gram-positive bacteria, while the (-) usnic acid has typical activity as a natural herbicide [8]. Moreover, usnic acid also has a significant activity against anaerobic Gram positive bacteria including Propionibacterium species [9,10]. Propionibacterium acne, a Gram-positive and facultative anaerobic bacterium, is one of the normal flora on the skin that in certain conditions can cause inflammation by producing lipases which break down fatty acids free of skin lipids, known as acnes [11]. A study has confirmed that usnic acid from Usnea barbata has ability to inhibit the growth of $P$. acnes at concentration $\geq 1 \mu \mathrm{g} / \mathrm{mL}$ [12].

There are numerous activities of usnic acid, yet its availability in the market for pharmaceutical products is still limited. In Indonesia, there is only one commercial product that has been 
marketed-Cream Scabicid ${ }^{\circledR}$ which contained 1\% usnic acid. This finite number of product is likely due to low solubility of usnic acid in water $(0.01 \mathrm{~g} / 100 \mathrm{~mL})$ [8]. Some efforts have been done to increase the solubility of usnic acid, such as complex formation using cyclodextrin [13], microencapsulation using polymer PLGA [14], milling process [15] and preparation in solid dispersion using HPMC [16]. Our recent study has shown enhancement of usnic acid by preparing it in solid dispersion using poly-vinyl-pirolidon (PVP) K-30 and its potency as an anti-oxidant was in accordance with the solubility result [17].

To the best of our knowledge, the was only one application of usnic acid as an anti-acne that has been investigated and patented by converting usnic acid into salt form or metal salt [18]. Meanwhile, one of the most favourable preparations used for handling acne is hydrogel. Hydrogel offers convenience in used and has more attractive appearance due to its transparency compared to other preparations. Moreover, hydrogel is easily washed out and give cool sensation during application on skin due to water content of the base. Therefore, gelling agents, such as chitosan, HPMC, carbomer, HPMC, polyvinyl alcohol (PVA) and sodium alginate, play important part in preparing hydrogel [12]. As a preliminary study, this research was focused on the pharmaceutical aspects of hydrogel contained usnic acid and the potency of usnic acid in order to confirm the activity against P. acnes.

Based on the above considerations, preparation of hydrogel containing intact usic acid and usnic acid-solid dispersion was carried out in this research. Solid dispersion was prepared using PVP K-30 in order to increase the solubility of usnic acid [17]. Prior to preparation of usnic acid hydrogel, concentration of gelling agents used is optimized. Hydrogel of usnic acid was then evaluated by homogeneity, $\mathrm{pH}$, stability and anti-bacterial test against $P$. acnes.

\section{Materials and Methods}

\subsection{Materials}

(+) Usnic acid (isolated from Usnea sp as explained in previous work [13]), PVP K-30 (Shin-Etsu Chemical, Tokyo, Japan), Aqupec HV-505 (Sumitomo Seika Chemicals Co., Ltd., Osaka, Japan), sodium alginate (PT. Kimia Farma, Jakarta, Indonesia), HPMC K 100 M (PT. Kimia Farma, Jakarta, Indonesia), glycerin (Bratachem, Jakarta, Indonesia), triethanolamine (Bratachem, Jakarta, Indonesia), nutrient agar (Merck, Darmstadt, Germany), Propionibacterium acnes ATCC 6919 (The Laboratory of Natural Resource of Sumatra, Padang, Indonesia), clindamycin phosphate gel (Medi-Klin, PT. Surya Dermato Medika, Surabaya, Indonesia), phosphate buffer (Merck, Darmstadt, Germany), chloroform (Merck, Darmstadt, Germany), ethanol (Bratachem, Jakarta, Indonesia) and distilled water.

\subsection{Optimization of Gelling Agent for Hydrogel Base}

Formulation of hydrogel base was prepared using three different gelling agents which were Aqupec 505 HV, Sodium alginate and HPMC K 100M at different concentration, as seen in Table 1. Hydrogel base was prepared by dispersing the gelling agent in distilled water until its swelling well.

\subsection{Evaluation of Hydrogel Base}

Each hydrogel base was evaluated using several parameters included: organoleptic test by observed its appearance visually; homogeneity test by dispersed about $1 \mathrm{~g}$ of each hydrogel sample was on an object glass and observed its homogeneity; $\mathrm{pH}$ measurement by diluted hydrogel into $1 \%$ concentration and $\mathrm{pH}$ was determined using $\mathrm{pH}$ meter digital (Hanna Instruments, Woonsocket, RI, USA); viscosity test by using a Brookfield viscometer (Ametek, Berwyn, PA, USA); and wash out test by applying $1 \mathrm{~g}$ each hydrogel to the hand then washed by water. 
Table 1. Preparation of hydrogel base.

\begin{tabular}{cccccccccc}
\hline \multirow{2}{*}{ Materials } & \multicolumn{3}{c}{ Formula 1 } & \multicolumn{3}{c}{ Formula 2 } & \multicolumn{3}{c}{ Formula 3 } \\
\cline { 2 - 10 } & $\mathbf{1 a}$ & $\mathbf{1 b}$ & $\mathbf{1 c}$ & $\mathbf{2 a}$ & $\mathbf{2 b}$ & $\mathbf{2 c}$ & 3a & 3b & 3c \\
\hline Aqupec HV-505 (\%) & 0.15 & 0.175 & 0.20 & - & - & - & - & - & - \\
Sodium alginate (\%) & - & - & - & 1.5 & 1.75 & 2 & - & - & - \\
HPMC K 100 M (\%) & - & - & - & - & - & - & 1.5 & 1.75 & 2 \\
Glycerin (\%) & 10 & 10 & 10 & 10 & 10 & 10 & 10 & 10 & 10 \\
TEA (\%) & 0.4 & 0.4 & 0.4 & - & - & - & - & - & - \\
Distilled water ad (\%) & 100 & 100 & 100 & 100 & 100 & 100 & 100 & 100 & 100 \\
\hline
\end{tabular}

$\mathrm{a}, \mathrm{b}$, and $\mathrm{c}$ are the variation of gelling agents concentration used in this study.

\subsection{Preparation Solid Dispersion}

Solid dispersion of usnic acid PVP K-30 was prepared as described in previous work [15]. Usnic acid and PVP K-30 at ratio 1:2 (w/w) were dispersed in $100 \mathrm{~mL}$ distilled water and stirred until homogenous. The mixture was then frozen using liquid nitrogen prior to drying process and continued to primary and secondary drying in freeze dryer apparatus (Christ Alpha 1-2 LD Plus, Osterode, Germany). The dried powder was then kept in a desiccator.

\subsection{Preparation and Evaluation of Hydrogel Usnic Acid (UA) and Usnic Acid in Solid Dispersion (UA-SD)}

The optimum concentration of each gelling agent was prepared for hydrogel containing intact usnic acid and usnic acid in solid dispersion. The amount of usnic acid dispersed in hydrogel was equivalent to $1 \%(w / w)$, so that the amount of usnic acid-solid dispersion was $3 \%(w / w)$. Each of optimal concentration of gelling agent was used in this hydrogel preparation. Furthermore, hydrogel preparations were evaluated for organoleptic test, homogeneity, $\mathrm{pH}$ and viscosity as described in evaluation of hydrogel base.

\subsection{Spreadability and Syneresis Test}

Spreadability test was conducted by placing about $0.5 \mathrm{~g}$ of hydrogel on transparent glass equipped with on a graph paper. The hydrogel was covered with transparent plastic and given a certain load $(1,3,5$ and $7 \mathrm{~g})$ for $15 \mathrm{~s}$. The diameter was measured after being given a load. In addition, syneresis test was done by storing the hydrogel at $10^{\circ} \mathrm{C}$ for 24,48 and $72 \mathrm{~h}$. Each hydrogel was placed on a cup to hold water released from the gel during storage. Syneresis value was calculated by measuring the weight loss during storage then compared to the initial weight.

\subsection{Usnic Acid Assay in Hydrogel}

The amount of usnic acid in hydrogel was determined by a spectrophotometer UV-Vis (Shimadzu, Japan) at maximum absorption length in phosphate buffer. About $1 \mathrm{~g}$ of each hydrogel was dissolved with $100 \mathrm{~mL}$ phosphate buffer $\mathrm{pH} 7.4$ and homogenized by sonication for $2 \mathrm{~h}$. The sample was then filtered and measured the absorbance at $289 \mathrm{~nm}$. The amount of usnic acid was then calculated based on linear regression.

\subsection{Cycling and Stability Test}

Cycling test: The hydrogel was tested for stability against cooling condition. Each sample was stored at temperature of $0-4{ }^{\circ} \mathrm{C}$ for $24 \mathrm{~h}$. The homogeneity of each sample was observed and $\mathrm{pH}$ was determined after the cycling test.

Stability test: Each sample of hydrogel was kept in at room temperature for 8 weeks. The stability of sample was observed every week including the physical appearance, homogeneity and $\mathrm{pH}$ test. 


\subsection{In Vitro Antibacterial Activity}

One $\mathrm{ml}$ of Propionibacterium acne suspension stock was put into a sterilized petri dish and added nutrient agar medium. The mixture was homogenized. About $10 \mathrm{mg}$ of each hydrogel sample was then put on the wells that has been prepared and incubated for $24 \mathrm{~h}$ at $37^{\circ} \mathrm{C}$. The ability of hydrogel samples to inhibit the growth of Propionibacterium acne was determined by measuring diameter inhibition. As positive and negative controls, a marketed gel containing clindamycin phosphate $1.2 \%$ (Medi-klin) and hydrogel base were tested using the same procedure.

\section{Results}

\subsection{Optimization of Hydrogel Base}

The result of hydrogel base optimization is shown in Table 2. All the hydrogel showed transparent and homogenous gel. Moreover, hydrogel had $\mathrm{pH}$ in a range 5.4-6.4 which is acceptable in preparing hydrogel. However, the viscosity of the F1a was the lowest which was relatively as liquid than gel. This result was likely due to insufficient amount of gelling agent used to prepare the hydrogel as described in product description [19], thus the concentration of Aqupec hydrogel influenced the viscosity. The wash out result denoted that the higher concentration of gelling agent, the more water need to wash the gel out of the skin. Thus, preparation of hydrogel containing intact usnic acid (UA) and usnic acid-solid dispersion (UA-SD) was carried out using F1b, F2a and F3a.

Table 2. Result of hydrogel base optimization.

\begin{tabular}{cccccc}
\hline No. & Hydrogel Base & Homogeneity & $\mathbf{p H}$ & Volume of Wash out & Viscosity \\
\hline 1 & F1a & Homogenous & 6.33 & $16 \mathrm{~mL}$ & $259.07 \mathrm{cps}$ \\
2 & F1b & Homogenous & 6.20 & $17 \mathrm{~mL}$ & $2595.39 \mathrm{cps}$ \\
3 & F1c & Homogenous & 6.53 & $18 \mathrm{~mL}$ & $3703.75 \mathrm{cps}$ \\
4 & F2a & Homogenous & 5.40 & $32 \mathrm{~mL}$ & $3815.19 \mathrm{cps}$ \\
5 & F2b & Homogenous & 5.37 & $37 \mathrm{~mL}$ & $5115.17 \mathrm{cps}$ \\
6 & F2c & Homogenous & 6.00 & $40 \mathrm{~mL}$ & $14,203.22 \mathrm{cps}$ \\
7 & F3a & Homogenous & 5.80 & $40 \mathrm{~mL}$ & $5544.87 \mathrm{cps}$ \\
8 & F3b & Homogenous & 5.40 & $50 \mathrm{~mL}$ & $9811.03 \mathrm{cps}$ \\
9 & F3c & Homogenous & 5.40 & $60 \mathrm{~mL}$ & $15,811.03 \mathrm{cps}$ \\
\hline
\end{tabular}

\subsection{Hydrogel of Usnic Acid and Usnic Acid-Solid Dispersion}

The hydrogel contained usnic acid and usnic acid-solid dispersion showed a yellowish gel which is shown in Figure 1. The result of homogeneity, $\mathrm{pH}$, viscosity and usnic acid content in hydrogel usnic acid and usnic acid-solid dispersion is shown in Table 3. The hydrogel of intact usnic acid (UA) was not homogenous while usnic acid-solid dispersion (UA-SD) was homogenous. This result has been predicted since the intact usnic acid crystal could not be well dispersed in hydrogel base. Meanwhile, the addition of usnic acid in hydrogel influence the $\mathrm{pH}$ result. Usnic acid is a weak acid that has $\mathrm{pKa}$ 4.4 [20]. Moreover, PVP K-30 was used to enhance the solubility of usnic acid [17], which impacted in reducing the viscosity of hydrogel. This phenomenon was also observed in other study [21,22], in which PVP maintains adhesion and limits of the physiological range. The amount of usnic acid in hydrogel was almost close to each formula which indicated that all intact usnic acid and usnic acid-solid dispersion has the same amount in hydrogel preparation. 


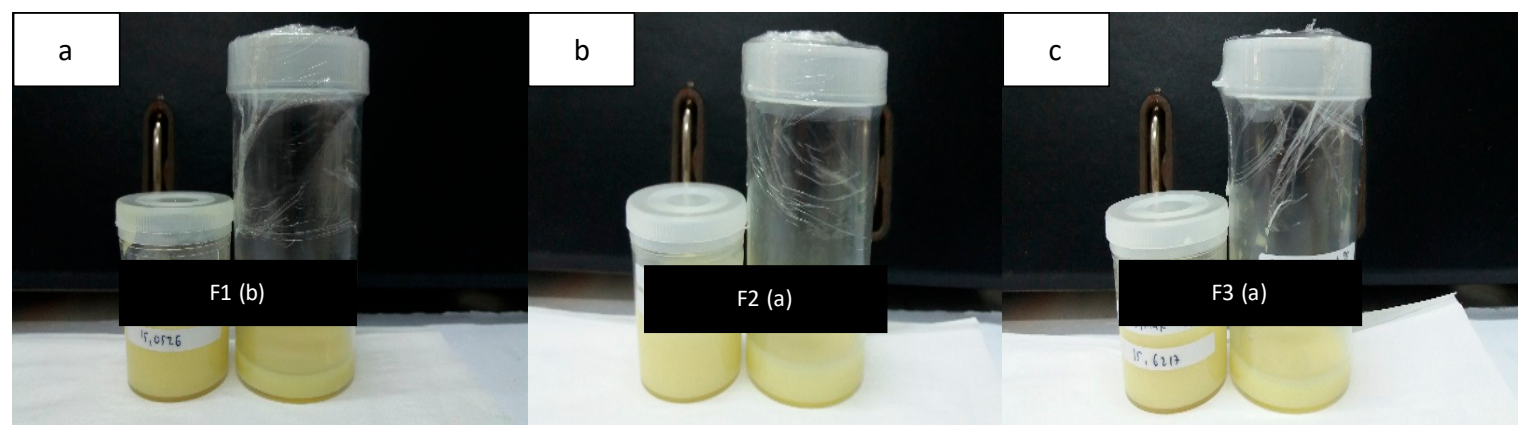

Figure 1. Hydrogels of usnic acid in different gelling agent (a) Aqupec, (b) sodium alginate, (c) HPMC.

Table 3. Result of hydrogel test.

\begin{tabular}{ccccc}
\hline Formula & Homogeneity & $\mathbf{p H}$ & Viscosity (cps) & Usnic Acid Assay (\%) \\
\hline F1b UA & No & $5.63 \pm 0.09$ & 2328.67 & $97.56 \pm 0.19$ \\
F1b UA-SD & Homogeneous & $5.67 \pm 0.05$ & 2270.74 & $99.23 \pm 0.29$ \\
F2a UA & No & $5.70 \pm 0.08$ & 2038.95 & $96.94 \pm 0.51$ \\
F2a UA-SD & Homogeneous & $5.50 \pm 0.08$ & 2017.03 & $98.19 \pm 0.10$ \\
F3a UA & No & $5.67 \pm 0.05$ & 3612.63 & $96.90 \pm 0.29$ \\
F3a UA-SD & Homogeneous & $5.50 \pm 0.14$ & 3635.04 & $97.77 \pm 0.29$ \\
\hline
\end{tabular}

Spreadability and syneresis test of hydrogel UA and UA-SD were also conducted to characterize the hydrogel as seen in Table 4. The spreadability value was corresponding to the viscosity result in previous evaluation. According to the result, the lower viscosity of hydrogel the greater ability to spread over. Meanwhile, syneresis is the ability of gel to be shrinkage due to change in temperature. The syneresis result of all hydrogels were similar.

Table 4. Spreadability and syneresis test result.

\begin{tabular}{ccccccccc}
\hline \multirow{2}{*}{ Formula } & \multicolumn{4}{c}{ Spreadability $\mathbf{( c m )}$} & \multicolumn{3}{c}{ Syneresis $\mathbf{( g )}$} \\
\cline { 2 - 9 } & Load 0 g & Load 1 g & Load 3 g & Load 5 g & Load 7 g & $\mathbf{2 4} \mathbf{~ h}$ & $\mathbf{4 8 ~ h}$ & $\mathbf{7 2 ~ h}$ \\
\hline F1b UA & 1.90 & 2.30 & 2.75 & 3.25 & 3.90 & 11.20 & 11.13 & 11.11 \\
F1b UA-SD & 2.85 & 3.45 & 3.95 & 4.45 & 5.10 & 11.18 & 11.15 & 11.14 \\
F2a UA & 1.85 & 2.35 & 2.70 & 2.85 & 3.00 & 11.05 & 11.37 & 11.31 \\
F2a UA-SD & 2.05 & 2.45 & 2.70 & 2.95 & 3.10 & 11.03 & 11.03 & 10.93 \\
F3a UA & 2.20 & 2.70 & 3.00 & 3.20 & 3.40 & 11.02 & 11.95 & 10.95 \\
F3a UA-SD & 2.40 & 2.85 & 3.15 & 3.55 & 3.65 & 11.04 & 10.94 & 11.01 \\
\hline
\end{tabular}

The result of cycling test in Table 5 indicated the stability of hydrogel under cool temperature, while stability of hydrogel at room temperature for eight weeks can be seen in Table 6 . The cycling test did show similar result of two parameters before and after the test. Similarly, the stability test was relatively the same after eight-week storage which suggested all hydrogel was stable.

Table 5. Cycling test result.

\begin{tabular}{ccccc}
\hline \multirow{2}{*}{ Formula } & \multicolumn{2}{c}{ pH } & \multicolumn{2}{c}{ Homogeneity } \\
\cline { 2 - 5 } & Before & After & Before & After \\
\hline F1b UA & $5.63 \pm 0.09$ & $5.67 \pm 0.00$ & No & No \\
F1b UA-SD & $5.67 \pm 0.05$ & $5.67 \pm 0.03$ & Homogeneous & Homogeneous \\
F2a UA & $5.70 \pm 0.08$ & $5.63 \pm 0.05$ & No & No \\
F2a UA-SD & $5.50 \pm 0.08$ & $5.47 \pm 0.05$ & Homogeneous & Homogeneous \\
F3a UA & $5.67 \pm 0.05$ & $5.63 \pm 0.05$ & No & No \\
F3a UA-SD & $5.50 \pm 0.14$ & $5.20 \pm 0.02$ & Homogeneous & Homogeneous \\
\hline
\end{tabular}


Table 6. Stability test at room temperature.

\begin{tabular}{ccccc}
\hline \multirow{2}{*}{ Formula } & \multicolumn{4}{c}{ pH Homogeneity } \\
\cline { 2 - 5 } & Week 1 & Week 2 & Week 4 & Week 8 \\
\hline F1b & 6.30 Homogeneous & 6.20 Homogeneous & 6.20 Homogeneous & 6.20 Homogeneous \\
F1b UA & 5.63 No & 5.81 No & 5.83 No & 5.83 No \\
F1b UA-SD & 5.67 Homogeneous & 5.63 Homogeneous & 5.63 Homogeneous & 5.63 Homogeneous \\
F2a & 6.60 Homogeneous & 6.30 Homogeneous & 6.00 Homogeneous & 6.00 Homogeneous \\
F2a UA & 5.50 No & 5.50 No & 5.50 No & 5.47 No \\
F2a UA-SD & 5.70 Homogeneous & 5.70 Homogeneous & 5.70 Homogeneous & 5.70 Homogeneous \\
F3a & 5.83 Homogeneous & 5.73 Homogeneous & 5.73 Homogeneous & 5.73 Homogeneous \\
F3a UA & 5.50 No & 5.43 No & 5.43 No & 5.43 No \\
F3a UA-SD & 5.57 Homogeneous & 5.57 Homogeneous & 5.57 Homogeneous & 5.57 Homogeneous \\
\hline
\end{tabular}

\subsection{In Vitro Antibacterial Assay}

The result of previous evaluations was anticipated to the antibacterial activity of usnic acid in hydrogel preparation. The diameter zone inhibition of each sample was correlated to the activity of antibacterial assay against P. acne, which is shown in Table 7 and Figure 2.

(a)

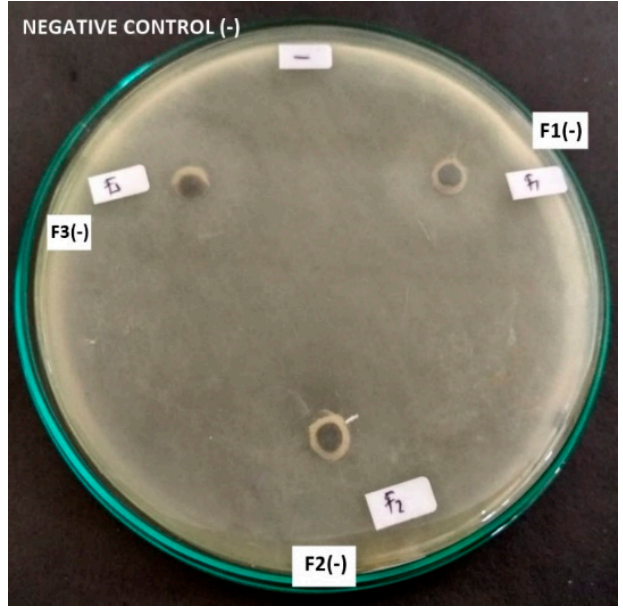

(c)

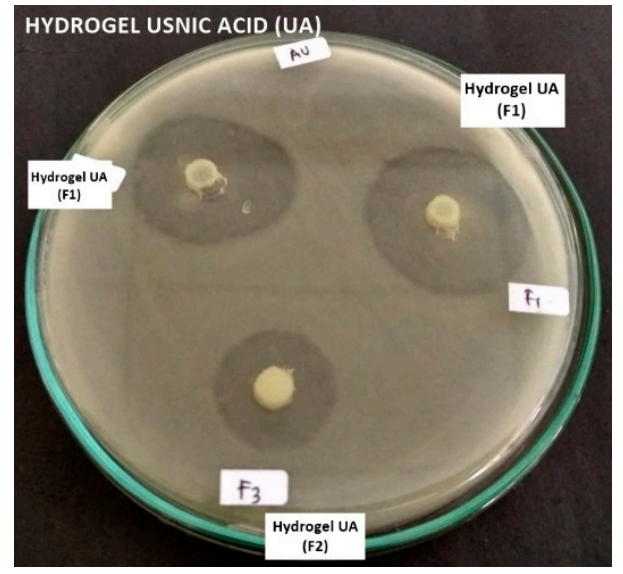

(b)

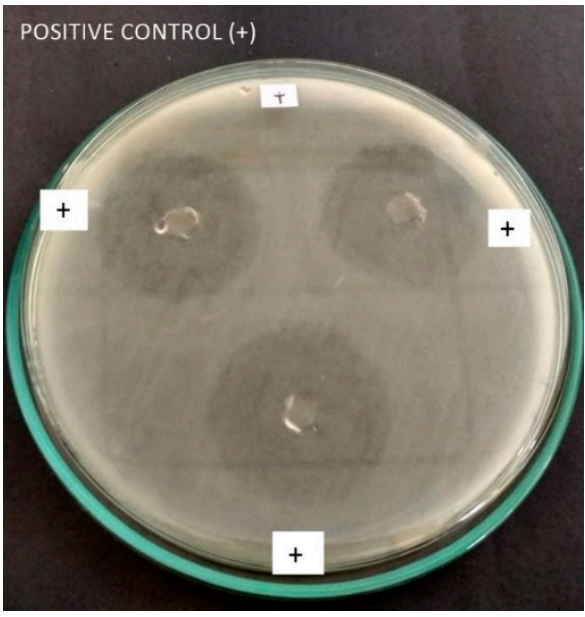

(d)

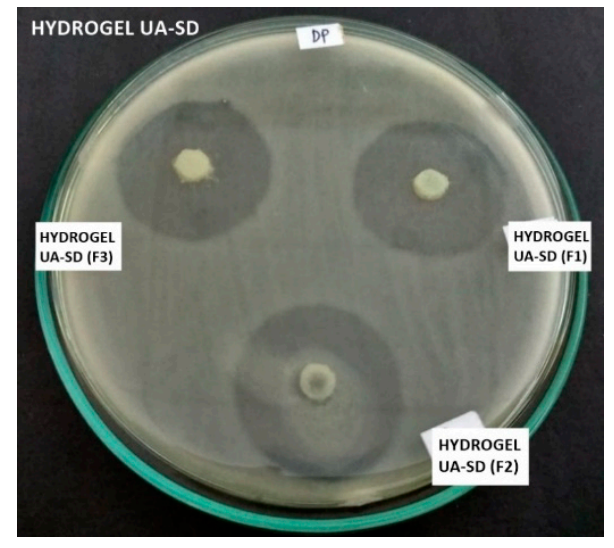

Figure 2. Result of antibacterial test against Propionibacterium acne. 
Table 7. Result of anti-bacterial assay.

\begin{tabular}{cc}
\hline Formula & Diameter Inhibition $(\mathbf{m m}) \pm$ SD \\
\hline F1b & $0 \pm 0.00$ \\
F1b UA & $30 \pm 0.05$ \\
F1b UA-SD & $32 \pm 0.05$ \\
F2a & $0 \pm 0.00$ \\
F2a UA & $29 \pm 0.05$ \\
F2a UA-SD & $30 \pm 0.05$ \\
F3a & $0 \pm 0.00$ \\
F3a UA & $20 \pm 0.05$ \\
F3a UA-SD & $26 \pm 0.05$ \\
Positive control $(+)$ & $30 \pm 0.05$ \\
\hline
\end{tabular}

All the hydrogel base or negative control showed no inhibition zone which indicated that no activity of antibacterial activity, see Figure 2a. Meanwhile, the positive control which used clindamycin gel shows about $30 \mathrm{~mm}$ diameter zone inhibition, see Figure $2 \mathrm{~b}$. The largest diameter inhibition was the hydrogel contained usnic acid-solid dispersion using Aqupec as the gelling agent. This result pointed that the hydrogel of usnic acid which prepared with different gelling agents had the same activity against $P$. acnes compared to the marketed and synthetic antibiotics. The potency of usnic acid as antibacterial is owing to the phenolic groups that known to have antibacterial activity [23]. In addition, the enhancement of antimicrobial activity in solid dispersion against bacteria was also showed in solid dispersion of usnic acid-polyacrilamide [24].

\section{Conclusions}

Preparation of hydrogel is influenced by the form of usnic acid used, which solid dispersion of usnic acid with PVP K-30 provides better result in appearance compared to intact usnic acid. PVP K-30 has not only increased the solubility of usnic acid but also influenced the homogeneity of usnic acid in hydrogel. The hydrogels were relatively stable after eight-weeks storage. The antibacterial activity against Propionibacterium acne by hydrogel of usnic acid and usnic acid-solid dispersion was almost similar to marketed gel contained synthetic antibiotic, which is a promising result for further study.

Author Contributions: Design this research was led by A.B. The preparation and evaluation of hydrogel was done by Afifah. The isolation of usnic acid from Usnea sp was done by A.B. and F.I. The data were analysed by L.F. and Afifah. The manuscript was written by L.F., Afifah and F.I.

Funding: This research was funded by Andalas University, grant number No. 24/UN.16.17/PP.RGB/LPPM/2018.

Acknowledgments: We gratefully acknowledge Andalas University for financial support and Dr. Erizal Zaini for his contribution in preparing solid dispersion of usnic acid.

Conflicts of Interest: The authors declare no conflict of interest. The funders had no role in the design of the study; in the collection, analyses or interpretation of data; in the writing of the manuscript or in the decision to publish the results.

\section{References}

1. Madamombe, I.T.; Afolayan, A.J. Evaluation of Antimicrobial Activity of Extracts from South African Usnea barbata. Pharm. Biol. 2003, 43, 199-202. [CrossRef]

2. Perry, N.B.; Benn, M.H.; Brennan, N.J.; Burgess, E.J.; Ellis, G.; Galloway, D.J.; Lorimer, S.D.; Tangney, R.S. Antimicrobial, antiviral and cytotoxic activity of New Zealand lichens. Lichenologist 1999, 6, 627-636. [CrossRef]

3. Campanella, L.; Delfini, M.; Ercole, P.; Iacoangeli, A.; Risuleo, G. Molecular characterization and action of usnic acid: A drug that inhibits proliferation of mouse polyomavirus in vitro and whose main target is RNA transcription. Biochimie 2002, 84, 329-334. [CrossRef] 
4. Mayer, M.; O’Neill, M.A.; Murray, K.E.; Santos-Magalhães, N.S.; Carneiro-Leão, A.M.A.; Thompson, A.M.; Appleyard, V.C.L. Usnic acid: A non-genotoxic compound with anti-cancer properties. Anticancer. Drugs 2005, 16, 805-809. [CrossRef] [PubMed]

5. Behera, B.C.; Verma, N.; Sonone, A.; Makhija, U. Antioxidant and antibacterial activities of lichen Usnea ghattensis in vitro. Biotechnol. Lett. 2005, 27, 991-995. [CrossRef] [PubMed]

6. Okuyama, E.; Umeyama, K.; Yamazaki, M.; Kinoshita, Y.; Yamamoto, Y. Usnic acid and diffractaic acid as analgesic and antipyretic components of Usnea diffracta. Planta Med. 1995, 61, 113-115. [CrossRef] [PubMed]

7. Vijayakumar, C.S.; Viswanathan, S.; Kannappa Reddy, M.; Parvathavarthini, S.; Kundu, A.B.; Sukumar, E. Anti-inflammatory activity of (+)-usnic acid. Fitoterapia 2000, 71, 564-566. [CrossRef]

8. Cocchietto, M.; Skert, N.; Nimis, P.; Sava, G. A review on usnic acid, an interesting natural compound. Naturwissenschaften 2002, 89, 137-146. [CrossRef] [PubMed]

9. Ingólfsdóttr, K. Usnic acid. Phytochemistry 2002, 61, 729-736. [CrossRef]

10. Parsaeimehr, A.; Martinez-Chapa, S.O.; Parra-Saldívar, R. Medicinal Plants Versus Skin Disorders. In The Microbiology of Skin, Soft Tissue, Bone and Joint Infections; Elsevier: Amsterdam, The Netherlands, 2017; pp. 205-221.

11. Dessinioti, C.; Katsambas, A.D. The role of Propionibacterium acnes in acne pathogenesis: Facts and controversies. Clin. Dermatol. 2010, 28, 2-7. [CrossRef] [PubMed]

12. Ahmed, E.M. Hydrogel: Preparation, characterization and applications: A review. J. Adv. Res. 2015, 6, 105-121. [CrossRef] [PubMed]

13. Nikolić, V.; Stanković, M.; Nikolić, L.; Nikolić, G.; Ilić-Stojanović, S.; Popsavin, M.; Zlatković, S.; Kundaković, T. Inclusion complexes with cyclodextrin and usnic acid. J. Incl. Phenom. Macrocycl. Chem. 2013, 76, 173-182. [CrossRef]

14. Ribeiro-Costa, R.M.; Alves, A.J.; Santos, N.P.; Nascimento, S.C.; Gonçalves, E.C.P.; Silva, N.H.; Honda, N.K.; Santos-Magalhães, N.S. In vitro and in vivo properties of usnic acid encapsulated into PLGA-microspheres. J. Microencapsul. 2004, 21, 371-384. [CrossRef] [PubMed]

15. Zaini, E.; Nisak, R.K.; Utami, R.D.; Fitriani, L.; Ismed, F. Effect of milling on physicochemical properties of usnic acid isolated from usnea sp. Orient. J. Chem. 2017, 33, 3031-3036. [CrossRef]

16. Fitriani, L.; Afriyanti, I.; Afriyani, A.; Ismed, F.; Zaini, E. Solid Dispersion of Usnic acid-HPMC 2910 Prepared by Spray drying and Freeze drying Techniques. Orient. J. Chem. 2018, 34, 2083-2088. [CrossRef]

17. Fitriani, L.; Rismawati, E.; Umar, S.; Zaini, E. Solid Dispersion of Usnic Acid-PVP K30 and Evaluation of Antioxidant Activity. Rasayan J. Chem. 2018, 11, 1643-1648.

18. Eady, E.A.; Fitzgerald, D.J. Antibacterial or Anti-Acne Formulations Containing Usnic Acid or an Usnate and a Metal Salt. U.S. Patent Application No. 13/996,427, 28 November 2013.

19. Carbomer (HV-505, HV-505HC, HV-504, HV-501, HV-505E, HV-504E, HV-501E, HV-505ED). Available online: https:/ / www.sumitomoseika.co.jp/documents/pc_dts_aqupec.pdf (accessed on 4 December 2018).

20. Bessadóttir, M. The Effects of the Lichen Metabolites Usnic Acid and Protolichesterinic Acid on Energy and Lipid Metabolism in Cancer Cells. Ph.D. Thesis, University of Iceland, Reykjavík, Iceland, December 2014.

21. Małolepsza-Jarmołowska, K. Pharmaceutical assessment of thermosensitive hydrophilic gels with polyvinyl pyrrolidone K-30 containing lactic acid complexed with chitosan. Prog. Chem. Appl. Chitin Its Deriv. 2013, 18, 123-131.

22. Małolepsza-Jarmołowska, K. The Effect of Selected Polymers on the Properties of Thermosensitive Hydrophilic Gels Containing Lactic Acid Complexed with Chitosan. Prog. Chem. Appl. Chitin Its Deriv. 2010, 15, 135-142.

23. Nasri, H.; Bahmani, M.; Shahinfard, N.; Nafchi, A.M.; Saberianpour, S.; Kopaei, M.R. Medicinal plants for the treatment of acne vulgaris: A review of recent evidences. Jundishapur J. Microbiol. 2015, 8, e25580. [CrossRef] [PubMed]

24. Francolini, I.; Taresco, V.; Crisante, F.; Martinelli, A.; D’llario, L.; Piozzi, A. Water soluble usnic acid-polyacrylamide complexes with enhanced antimicrobial activity against Staphylococcus epidermidis. Int. J. Mol. Sci. 2013, 14, 7356-7369. [CrossRef] [PubMed]

(C) 2018 by the authors. Licensee MDPI, Basel, Switzerland. This article is an open access article distributed under the terms and conditions of the Creative Commons Attribution (CC BY) license (http:/ / creativecommons.org/licenses/by/4.0/). 